\title{
Quality improvement in hospitals' surgery-related processes: A systematic review
}

\author{
Tina Beyranvand ${ }^{1}$, Aidin Aryankhesal*1, Asgar Aghaei Hashjin ${ }^{1}$
}

\section{Abstract}

Background: There is a growing global movement toward quality and safety in healthcare and quality improvement (QI) in general surgery. The fundamentals of QI begin with an understanding of the underlying theoretical framework. This study aims to provide an overview of the existing QI models and frameworks for general surgery.

Methods: In this systematic review, published literature from January 2007 until September 2018 were retrieved from PubMed, Scopus, Web of Science and Embase databases, and Google Scholar using the MeSH terms related to QI and surgery. In total, 25 fulltext articles were finally included, and data extraction was based on research objectives.

Results: Nine models were identified for QI in general surgery. These models were categorized into two main groups: (i) conceptual models or frameworks designed for QI in industry and applied in surgery, and (ii) those designed specifically for QI in surgery. Identified QI models were more used for improving postoperative processes and pre-hospital trauma care, identifying causes of prolonged periods of stay and lowering LOS index, improving surgical antimicrobial prophylaxis and antibiotics administrating during surgery process, reducing and controlling infections, reducing complications, reducing mortality and morbidity, reducing waiting times and start time delays, reducing variability and improving surgical clinic experience, reducing costs, improving operating room efficiency by removing processes that add no value, and lowering per-capita costs.

Conclusion: According to the findings of this study, there are different models and frameworks with different aspects and dimensions for QI in surgery, which is recommended to use either of these models alone or with each other for specific circumstances. The use of these models in surgery is increasing, and it is recommended that these models could be used according to their functions in cases such as reducing the unnecessary use of resources, increasing the satisfaction of patients and their families with health care and improving the efficiency, safety and quality of healthcare in the surgical departments.

Keywords: Quality improvement, Improvement model, surgery, hospital, Systematic review

Conflicts of Interest: None declared

Funding: None

\section{*This work has been published under CC BY-NC-SA 1.0 license.}

Copyright $\odot$ Iran University of Medical Sciences

Cite this article as: Beyranvand T, Aryankhesal A, Aghaei Hashjin A. Quality improvement in hospitals' surgery-related processes: A systematic review. Med J Islam Repub Iran. 2019 (2 Dec);33:129. https://doi.org/10.47176/mjiri.33.129

\section{Introduction}

The WHO has highlighted the quality of health care as a key element in improving the health-centered outcomes and the efficiency and effectiveness of hospitals, and a framework for strengthening health systems, especially in

Corresponding author: Dr Aidin Aryankhesal, aryankhesal.a@iums.ac.ir

1. Department of Health Services Management, School of Health Management and Information Sciences, Iran University of Medical Sciences, Tehran, Iran resource-poor countries (1). Due to the rising costs and demand for healthcare, quality improvement has been a necessity and an opportunity for improvements in continuous monitoring, reduce repetitive processes, and elimi-

\section{$\uparrow$ What is "already known” in this topic:}

There is a growing global movement toward quality and safety in healthcare and quality improvement (QI) in general surgery. The identification of theoretical frameworks is the cornerstone of any QI program.

\section{$\rightarrow$ What this article adds:}

This is the first systematic review that aims to identify and evaluate QI models in surgery and provide an overview in this area. The results of this study can be used by health managers, researchers, and all those who are interested in quality improvement in hospitals. 
nate unnecessary health system processes (2, 3). Also throughout the last two decades, health care has faced steadily intensifying scrutiny of its safety, quality, and cost that has led to more attention to quality measurement and improvement (QI) programs (4-6).

In the health sector, hospitals comprise the largest proportion of health care expenditures and operation room activities tend to be the most resource intensive, thereby it has been an attractive target for QI initiatives (7). So there is a growing global movement toward quality and safety in healthcare and quality improvement initiatives in surgery (8). In surgery, emphasis on quality is also manifested in mandates from different governing bodies (9). Recent emphasis has been given to improving the quality of surgical care in low and middle-income countries (10). Evidence shows that surgical conditions are important global public health problems, and data suggest that essential surgical services can be delivered in a cost-effective manner in low and middle-income countries. Therefore, the WHO has expanded its interest in surgical care (11).

The fundamentals of QI begin with an understanding of the underlying theoretical framework (12). The identification of conceptual frameworks is the cornerstone of any QI program (13). From the standpoint of enacting change around any quality dimension, QI initiatives in healthcare should be structured around three components: a clear definition of quality and its various dimensions, a comprehensive methodology for measuring and comparing performance across these quality dimensions, and identification and effective implementation of the available models or tools within and outside the hospital for improving and assuring quality (14).

Using QI models in health care creates a systematic approach to problem solving, help providers to improve the process, facilitate teamwork, and create a clear plan to communicate at any time and also offer a set of tools, a powerful way to thinking about how to transform clinical operations to achieve better results for patients and healthcare teams and a framework for healthcare professionals to follow in implementing process improvement changes $(15,16)$. Given the economic climate both nationally and internationally, QI models in surgery constitute an emerging practice that should be considered at all levels of healthcare organizations, as they contribute to the financial viability and sustainability of the healthcare systems for future generations (17).

There are many models for QI in surgery. So far, various studies have been conducted about using QI models in surgery. A systematic review study was conducted in 2011 by Nicolay to review the application of QI methodologies from the manufacturing industry to surgical healthcare (18). Also, another review study in 2014 evaluated the effectiveness of two QI models in surgery (19). But the present study aims to identify and evaluate QI models in surgery and provide an overview in this area.

\section{Methods}

\section{Search method and article selection}

The purpose of this systematic review was to review QI models in surgery. Databases PubMed, Web of science,
Cochran library, Scopus, Embase, and Google scholar search engine were searched with the keywords quality improvement/ improvement of quality, operating room/ operation room/ theatre/ surgery, model/ framework and their synonyms from January 2007 to the end of September 2018 (Appendix 1). As the quality issue in surgery has been more considered by WHO and researchers (according to the "Results by year" chart in PubMed database) since 2007, this period was selected for the study (11).

The references of the included studies were examined. Only English articles were included. The search process was conducted in September 2018 for 4 months.

First, the titles and abstracts of the articles were screened, and data were extracted by two reviewers independently. Studies that did not have inclusion criteria were removed. Also, the quality of all steps was monitored by the team supervisor. Results were reported using the PRISMA flowchart (20).

97 studies of the 4941, were selected after reviewing the title and abstract. After reviewing the full-text of the articles and regarding the inclusion and exclusion criteria, 25 articles were selected.

Data extraction was performed based on study objectives. The data extraction table included general (first author, year of publication, country, and type of study) and specific variables (the type of used or presented model, the purpose of using the model, and expected results from the application or presentation of each model). Data were entered into Microsoft Excel.

\section{Inclusion and exclusion criteria}

We included all types of peer-reviewed researches. The inclusion criteria in the study were publications that developed or implemented at least a model or framework for quality improvement in all contexts of surgery. All types of studies published between January 1st, 2007 and September 31th, 2018, were included. Also, studies in English were included, but those published in a language other than English were excluded.

Given that our study design was a systematic scoping review, and our purpose was identifying QI models in surgery, so articles on quality assessment was not evaluated (21).

\section{Analysis and descriptive synthesis}

Data were extracted based on study objectives and analyzed qualitatively using the content analysis method (22). The main objective of our study was to investigate the type of used or proposed models for quality improvement in surgery. A descriptive synthesis was done. The studies were split into two main categories. The first category included studies that used one of the existing quality improvement models for surgery (models that entered from industry to surgical healthcare) and the second group included studies that provided a new model or framework for quality improvement in surgery. Finally, we designed a table to synthesize the findings that had 2 dimensions; one dimension is the type of QI model and another is expected outcomes from using them. 


\section{Results}

Ninety-seven out of 4941 papers were selected after screening based on titles and abstracts. Twenty-five articles were finally included in the review after the full-text screening, based on the inclusion and exclusion criteria (Fig. 1).

Table 1 shows the characteristics of the reviewed studies, including country, the type of model used or presented, the scope of the study, and the purpose of the application of these models.

From 25 included studies, 14 of them were conducted in USA, four in UK, three in Ireland, two in Canada, one in Italy and one in India. The largest number of studies published in 2015 and 2018, respectively.

In total, nine models were identified. These models were categorized according to their origin in two general groups: models designed for industry and applied in surgery (Group 1), and models designed specifically for surgery (Group 2) (Table 2).

\section{Description of QI models in surgery}

An overview of the identified QI models in surgery is presented in this section.

\section{Models designed for industry and applied in surgery}

PDSA (Plan-Do-Study-Act): PDSA model refers to a systematic approach to testing and measuring ideas in an iterative manner that may lead to an improvement in processes or outcomes. (23). This model includes the following steps: Plan (developing the required processes to achieving outcomes in accordance with expected goals), Do (implementation of the new process in small scale),
Study (measure and evaluate the new process and understand the differences between it and the expected outcomes), and Act (analyze the differences between observed and expected outcomes and determine the causes of these differences) (18).

In the reviewed studies, this model used in various surgical context and for objectives such as: to improve the quality of postoperative neonatal procedures, process mapping and finding improvable points in general surgery, to improve the quality of patient education after surgery, to identify the causes of long-term stay after surgery and reduce it, to improve surgical antimicrobial prophylaxis and infection control, to improve communication between patient and medical staff, to reduce patient waiting time before surgery, reduce complications, and improvements in processes and outcomes.

Six sigma: Six sigma refers to a rigorous methodology that seeks to improve the quality of the output of a process by identifying and removing the causes of defects and minimizing variability in providing a product or service. This model has the following steps: Define, Measure, Analysis, Improvement, and Control (DMAIC). This approach is increasingly used in health care and is used to improve the efficiency and reduce problems, and standardization of care processes (23).

In the reviewed studies, this model used for objectives such as: to improve the efficiency and standardization of care processes, process mapping and finding improvable points in general surgery, to improve efficiency in the operating room, to reduce the waiting time of the surgeon between each surgery, to reduce length of stay, infection control, to administrate antibiotics prescribing and use,

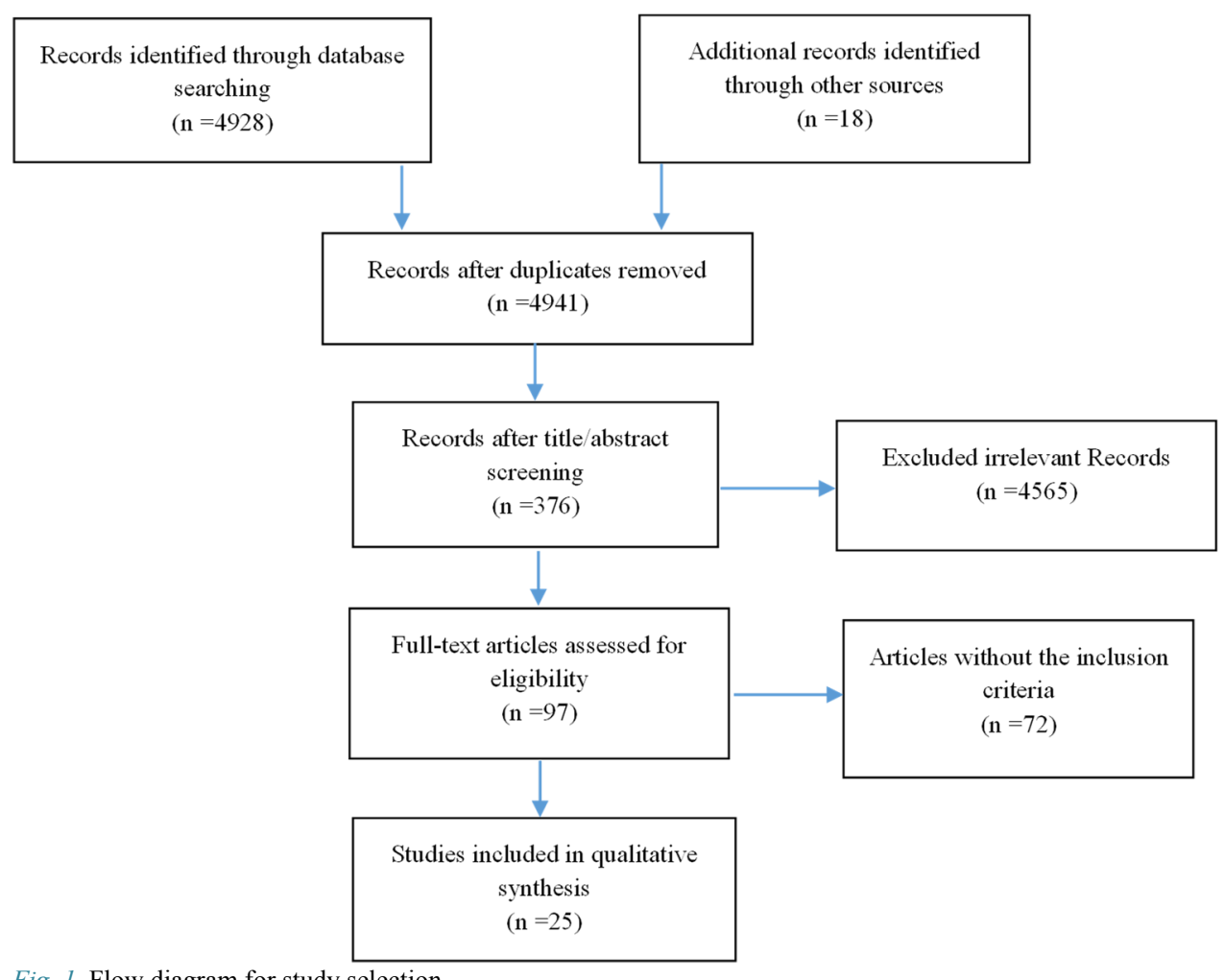


Table 1. Characteristics of Included Studies

\begin{tabular}{|c|c|c|c|c|}
\hline Author/ year & Country & Model & Field of surgery & Aim \\
\hline Newcombe/ 2018 & USA & PDSA & Intensive Care Unit & To improve postoperative neonatal nutritional practices \\
\hline Conaty/ 2018 & Ireland & PDSA & Orthopedic surgery & To improve surgical antimicrobial prophylaxis \\
\hline Divi/ 2018 & USA & PDSA & $\begin{array}{l}\text { Otolaryngology- } \\
\text { Head and Neck } \\
\quad \text { Surgery }\end{array}$ & To reduce the surgery time wasted \\
\hline Chandra/ 2018 & India & PDSA & Pediatric Surgery & $\begin{array}{l}\text { To reduce preoperative waiting-time by optimizing process } \\
\text { flow }\end{array}$ \\
\hline Newton/2017 & UK & PDSA & $\begin{array}{l}\text { A preoperative ward } \\
\text { in pediatric surgery }\end{array}$ & $\begin{array}{l}\text { To identify the different aspects of why children fasted for } \\
\text { prolonged periods in the institution }\end{array}$ \\
\hline Scott/ 2017 & USA & $\begin{array}{l}\text { Continuous quality } \\
\text { improvement (CQI) }\end{array}$ & $\begin{array}{l}\text { Pre-hospital emer- } \\
\text { gency care service }\end{array}$ & To improve pre-hospital trauma care \\
\hline Luckenbaugh/ 2017 & USA & $\begin{array}{l}\text { Collaborative quality } \\
\text { improvement }\end{array}$ & Urological surgery & $\begin{array}{l}\text { To improve urological care, with the goal of measuring and } \\
\text { improving the quality of care provided to patients }\end{array}$ \\
\hline Cameron/ 2016 & USA & $\begin{array}{l}\text { PDSA, Lean, Six } \\
\text { sigma }\end{array}$ & Pediatric surgery & $\begin{array}{l}\text { PDSA: To improve in processes or outcomes } \\
\text { Lean: To optimize efficiency by removing processes that } \\
\text { add no value } \\
\text { Six sigma: Utilize in healthcare to improve efficiency and } \\
\text { standardize care processes }\end{array}$ \\
\hline Hart/ 2016 & USA & $\begin{array}{l}\text { Framework for surgi- } \\
\text { cal improvement }\end{array}$ & Surgical fields & $\begin{array}{l}\text { To propose a surgical measurement framework that pro- } \\
\text { vides a systematic, longitudinal approach for identifying } \\
\text { key steps and processes in the management of surgical } \\
\text { condition }\end{array}$ \\
\hline Zimnicki/ 2015 & USA & PDSA & $\begin{array}{l}\text { Patients undergoing } \\
\text { planned stoma sur- } \\
\text { gery }\end{array}$ & $\begin{array}{l}\text { To enable staff nurses to perform preoperative stoma site } \\
\text { marking and education }\end{array}$ \\
\hline Robertson/ 2015 & UK & Lean & Plastic surgery & To improve surgical safety \\
\hline Buck/ 2015 & USA & PDSA & Pediatric surgery & $\begin{array}{l}\text { To reduce the intraoperative use of single-dose vials of } \\
\text { fentanyl }\end{array}$ \\
\hline Improta/ 2015 & Italy & Lean and Six Sigma & $\begin{array}{l}\text { Hip replacement } \\
\text { surgery }\end{array}$ & $\begin{array}{l}\text { To develop a clinical pathway which allows to improve } \\
\text { quality and to reduce costs in prosthetic hip replacement } \\
\text { surgery }\end{array}$ \\
\hline Minami/ 2015 & USA & $\begin{array}{l}\text { PDSA, Six Sigma, } \\
\text { Lean, and Lean-Six } \\
\text { Sigma }\end{array}$ & Surgical fields & $\begin{array}{l}\text { PDSA: To structure an iterative approach to change } \\
\text { Six sigma: To reduce variation and improve complex prob- } \\
\text { lems within large organizations } \\
\text { Lean: To eliminate waste } \\
\text { Lean-Six sigma: To remove the eight kinds of waste: time, } \\
\text { inventory, motion, waiting, over-production, over- } \\
\text { processing, defects, and skills }\end{array}$ \\
\hline Mason/ 2014 & UK & Lean and Six Sigma & General surgery & $\begin{array}{l}\text { To optimize outpatient efficiency and experience, improve } \\
\text { operating theatre efficiency, decrease operative complica- } \\
\text { tions, reduce mortality, limit unnecessary cost and length of } \\
\text { stay }\end{array}$ \\
\hline Marshall/ 2014 & Canada & $\begin{array}{l}\text { Continuous Quality } \\
\text { Improvement (CQI) }\end{array}$ & $\begin{array}{l}\text { Hip and knee re- } \\
\text { placement surgery }\end{array}$ & $\begin{array}{l}\text { To improve care, improve the patient experience, lower } \\
\text { per-capita cost }\end{array}$ \\
\hline Blackmore/ 2013 & USA & Lean & General surgery & $\begin{array}{l}\text { To improve quality and safety in surgical sterile instrument } \\
\text { processing }\end{array}$ \\
\hline Farrokhi/ 2013 & Ireland & Lean & $\begin{array}{l}\text { Invasive spine sur- } \\
\text { gery }\end{array}$ & $\begin{array}{l}\text { To improve quality and efficiency in operating room in- } \\
\text { strument availability }\end{array}$ \\
\hline Mazaleski/ 2011 & USA & PDSA & $\begin{array}{l}\text { Total joint replace- } \\
\text { ment surgery }\end{array}$ & $\begin{array}{l}\text { To organize and evaluate a weekly postoperative class for } \\
\text { support persons of patients who have undergone total joint } \\
\text { replacement surgery in an effort to enhance patient- and } \\
\text { family-centered care }\end{array}$ \\
\hline Nicolay/ 2011 & UK & $\begin{array}{l}\text { PDSA, SPC, CQI, } \\
\text { Six sigma, TQM, } \\
\text { (SQC), Lean, Lean } \\
\text { Six sigma }\end{array}$ & Surgical healthcare & $\begin{array}{l}\text { PDSA: Control infection, reduce complications } \\
\text { SPC: Reduce complication, reduce infection, analyze sur- } \\
\text { geon performance and set a benchmark and reduce waiting } \\
\text { time and Length Of Stay (LOS) } \\
\text { CQI: Improve quality indicators } \\
\text { TQM: Improve process of care } \\
\text { Six sigma: Antibiotics administrating, reduce start time } \\
\text { delays, reduce patient Length Of Stay (LOS) } \\
\text { Lean: reduce infection, improve appropriate use of antibiot- } \\
\text { ics, Reduce variability and improve surgical clinic experi- } \\
\text { ence, reduce patient Length Of Stay (LOS) }\end{array}$ \\
\hline
\end{tabular}

and to reduce start time delays.

Lean: Lean is a collection of philosophies and methods that helps to create maximum value through reducing the amount of waste and waiting times and optimal use of resources $(23,24)$. The main purpose of this model is to eliminate errors, efficiency improvement, and focus on analyzing a process and eliminating worthless or inefficient steps in them. This model has been increasingly used in healthcare to highlight costs and issues related to quality and safety. Also, the use of this model in surgery is recommended due to the nature of its costs and its high consumption (25-28). 


\begin{tabular}{|c|c|c|c|c|}
\hline Author/ year & Country & Model & Field of surgery & Aim \\
\hline Cima/ 2011 & USA & Lean and Six Sigma & $\begin{array}{l}\text { An entire surgical } \\
\text { suite }\end{array}$ & To improve operating room efficiency \\
\hline Sedlack/ 2010 & Ireland & $\begin{array}{l}\text { Six Sigma and Statistical } \\
\text { Process Control (SPC) }\end{array}$ & Colon Surgery & $\begin{array}{l}\text { To reduce surgeon waiting time between cases, and } \\
\text { length of stay (LOS) after colon surgery }\end{array}$ \\
\hline Gillaspie/2010 & USA & PDSA & $\begin{array}{l}\text { Total joint replace- } \\
\text { ment surgery }\end{array}$ & $\begin{array}{l}\text { To enhance patient and provider communication, } \\
\text { enhance patient education, and accurate provider } \\
\text { pain assessment }\end{array}$ \\
\hline Berry/ 2008 & USA & Proven Care & Cardiac surgery & $\begin{array}{l}\text { To decrease morbidity/mortality and readmission } \\
\text { rates }\end{array}$ \\
\hline DeGirolamo / 2007 & Canada & PDSA/ Six Sigma & $\begin{array}{l}\text { Emergency general } \\
\text { surgery }\end{array}$ & $\begin{array}{l}\text { To create process maps for small bowel obstruction } \\
\text { in an effort to identify potential areas for quality } \\
\text { improvement }\end{array}$ \\
\hline \multicolumn{3}{|c|}{ Models designed for industry and applied in surgery (Group 1) } & \multicolumn{2}{|c|}{ Models designed specifically for surgery (Group 2) } \\
\hline \multicolumn{3}{|c|}{ Plan- Do- Study- Act (PDSA) } & \multicolumn{2}{|c|}{ Proven Care model } \\
\hline \multicolumn{3}{|l|}{ Six Sigma } & \multicolumn{2}{|c|}{ Collaborative Quality Improvement model } \\
\hline \multicolumn{3}{|l|}{ Lean } & \multirow{2}{*}{\multicolumn{2}{|c|}{ C.K Hart framework }} \\
\hline \multicolumn{3}{|c|}{ Continuous Quality Improvement (CQI) } & & \\
\hline \multicolumn{5}{|c|}{ Total Quality Management (TQM) } \\
\hline \multicolumn{5}{|c|}{ Statistical Process Control (SPC) } \\
\hline
\end{tabular}

In the reviewed studies, this model was used to optimize performance by eliminating worthless and unnecessary processes, to improve surgical safety, to improve the quality and safety in the process of sterilization of the operating room equipment, to improve the quality and efficiency in access to the operating room equipment, to infection control, to improve the proper use of antibiotics, to reduce variability and improve surgical clinic experience, and to reduce length of stay.

SPC (Statistical Process Control): SPC model is a philosophy, strategy, and set of methods for continuous improvement of systems, processes, and outcomes that is based on the use of data. Using this model requires understanding the processes by mapping them, and then understanding the causes of the changes and fixing them when they occur. This model is more used to continuous monitoring of the processes and to identify potential problems, and as a tool to assess the impact of other quality improvement interventions (18).

In the reviewed studies, this model has been used for different cases, such as: to reduce waiting time, the LOS for postoperative patients, and side effects, to control infection, and to analyze the surgeon's performance.

TQM (Total Quality Management) and CQI (Continuous Quality Improvement): TQM and its extension, CQI, is a management philosophy to continuously improve the quality of products and processes in order to meet customers' expectations, which can be used to influence profitability, costs, patient and staff satisfaction, and clinical outcomes (29-31). So that the quality must be the responsibility of everyone involved in the production or the provision of the services, including manager, personnel, suppliers, and even clients themselves (32). CQI is an expansion the SPC model, and it should be designed and institutionalized within the process (4).

In the reviewed studies, these two models have been used to improve the quality indices, care processes, prehospital care, and patient experience and satisfaction, and also to reduce waiting times, and per capita cost.

In general, many of the mentioned models contains continuous and cyclic projects, but their sustainability is uncertain over time (18).

\section{Models designed specifically for surgery}

C.K Hart framework: This model provides a comprehensive surgical measurement framework, which facilitates the identification of outcomes, key steps and processes in the management of surgical conditions, and provides a context that allows clinicians to translate these measures into clinical improvement. The purpose of this model is developing an assessment framework for surgery, in order to improve the patient's interim and longterm outcomes. This framework will facilitate standardization of care processes and measures to achieve ideal outcomes. This framework facilitates improvement by focusing on three primary areas: (1) measurement of outcomes during each phase of care, (2) identification of reliable processes of care, (3) mitigation of complications. These three areas were selected as the key aspects necessary to build a useful framework (33).

Proven Care: This model focuses on the processes and redesigns them. This model was developed in three phases: (1) review and validation of best practice evidence, (2) redesign of the process, (3) implementing the new process.

From this model's perspective, quality improvement is equal to process improvement. This model is suitable for episodic surgical interventions. Although this model has been used to improve the quality of the heart surgery, however, it can be used for the quality improvement in all surgical fields and interventions. To better performance, strong communication tools and timely feedback are required. This model may be difficult to run when the independency of the physician and surgical department personnel is low. Also, this model is not functional for high-volume surgical departments and because it has been 
implemented in a small community, generalization problems may occur (34).

Collaborative quality improvement: Collaborative quality improvement model focuses on cooperation in surgical quality improvement. This model utilizes a 'measuring to improve' philosophy consisting of core principles - quality data collection, feedback to physicians and practices, dissemination and implementation of strategies amongst collaborative members - with the goal of improving the care provided, treatment outcomes and costs. It is a comprehensive model that has two main dimensions: collaborative support and surgical quality improvement framework. The initial phase of this model is a QI need assessment, which ultimately leads to outcome improvements by changing the system and processes. Actually, in this model, the quality improvement framework and collaborative support are complementary (35).

\section{Data synthesis}

After analyzing the studies, a table was drawn for synthesizing the results. One dimension is the type of QI model and another is expected outcomes from the application of these models in different surgery fields. (Table 3).

According to the results, identified QI models were more used to improve postoperative processes and prehospital trauma care, identify causes of prolonged periods of stay and reduce LOS index, improve and administrate surgical antimicrobial prophylaxis and antibiotics during surgery process, reduce and control infections, reduce complications, reduce mortality and morbidity, reduce waiting times and start time delays, reduce variability and improve surgical clinic experience, reduce costs, improve operating room efficiency by removing processes that add no value, and decrease per-capita costs.

Also these models rarely used for important purposes like: enabling staff and educating them to perform preoperative activities, enhancing patient and provider communication, improving patient education, and accurate pain assessment, reducing readmission rate, analyzing surgeon performance, improving surgical safety, improving quality and efficiency in operating room instrument availability, and facilitating standardization of processes of care, as well as care evaluating to achieve ideal outcomes.

\section{Discussion}

The use of the identified models is often based on process mapping. Since implementing these models will be easier through designing and tracing the process. Each of these models can be used together or alone as an independent framework to guide healthcare QI projects (9). As noted in the result, two principal groups of the models were found by reviewing studies.

The first group included the models that entered the surgery from industry, and another group was those that presented to QI in surgical sections only. Most included studies that showed the positive impact of interventions, used the first group models, and there is a little evidence about unsuccessful attempts or implementation barriers to using these models in healthcare (36). Indeed, these models can be QI key in surgery and also be effective in reducing costs. These models have been successfully applied in various fields and aspects of surgery, especially in

\begin{tabular}{|c|c|c|c|c|c|c|c|c|c|c|c|c|c|c|c|c|c|c|c|c|}
\hline Outcome & 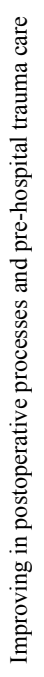 & 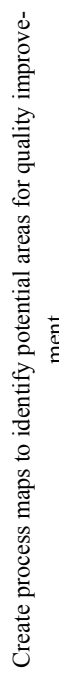 & 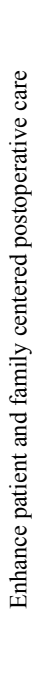 & 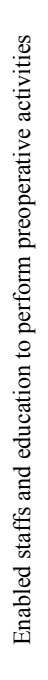 & 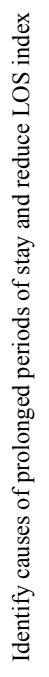 & 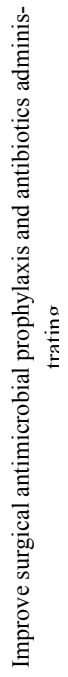 & 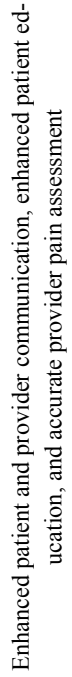 & 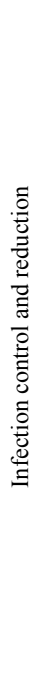 & 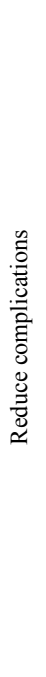 & 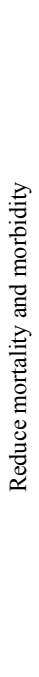 & 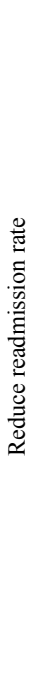 & 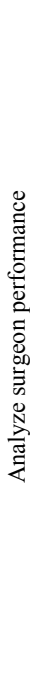 & 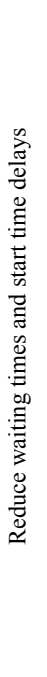 & 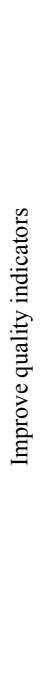 & 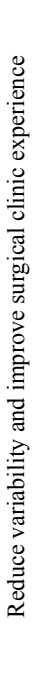 & 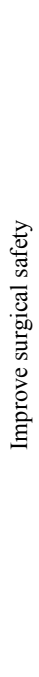 & 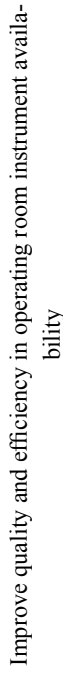 & 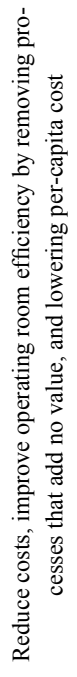 & 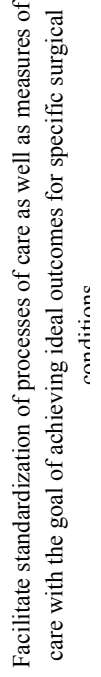 & 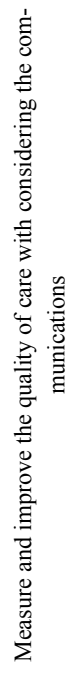 \\
\hline Lean & $*$ & & & & $*$ & $*$ & & * & * & * & & & & & $*$ & $*$ & $*$ & * & & \\
\hline PDSA & $*$ & $*$ & $*$ & $*$ & $*$ & $*$ & $*$ & $*$ & $*$ & & & & $*$ & & & & & & & \\
\hline Six Sigma & $*$ & $*$ & & & $*$ & $*$ & & & * & * & & & * & & * & & & * & & \\
\hline SPC & & & & & $*$ & & & $*$ & $*$ & & & $*$ & $*$ & & & & & * & & \\
\hline CQI & $*$ & & & & & & & & & & & & & $*$ & $*$ & & & * & & \\
\hline $\begin{array}{l}\text { Collaborative } \\
\text { quality im- } \\
\text { provement }\end{array}$ & $*$ & & & & & & & & & & & & & & & & & $*$ & & $*$ \\
\hline TQM & $*$ & & $*$ & & & & & & & & & & & & & & & * & & \\
\hline C.K. Hart & $*$ & & & & & & & & $*$ & & & & & & & & & & * & \\
\hline Proven care & $*$ & & & & & & & & & $*$ & $*$ & & & & & & & & & $*$ \\
\hline
\end{tabular}


repetitive processes, such as infection control and reduce the preoperative delay (18).

The PDSA model in the first category is often used for small QI projects or changes, or rapid assessment of interventions, as well as for continuous feedback to overcome the resistances (37-39). This model is also more used to reduce waiting times. The use of this model in various studies has confirmed its efficacy, feasibility and appropriateness, and immediate effect on the quality of care (40). The Lean model has been used more to improve the quality of medical equipment in the operating room, and Six Sigma model always has been used to reduce the variance in the operating room processes through a set of process criteria and statistical analyses, in order to improve the efficiency and quality. The strengths of Lean and Six Sigma models are roughly quadrupled when used together in a complex healthcare environment $(19,27)$.

The SPC model was more used to reduce, improve and control surgical procedures such as waiting time, and length of stay in the surgery department (41). Indeed, all models in the first group use different terms, but their approach is based on data and their purpose is to improve care processes (9). There is also an overlap between the models. For example, the elements of the PDSA and SPC are similar to CQI, TQM, six sigma and Lean, or SPC itself is a model, but it can be used as a real-time measurement tool for other models (18).

The first group of QI models can easily identify and resolve process control problems that occur in surgery (41). Also, one of the strengths of these models is that they are flexible, and they can be used for similar challenges at a specific time and place. All of them use a systematic approach with a flexible process to QI, which can be used for a wide range of outcomes between different patient groups and different surgical fields (19).

Interrupted time series analysis before and after using these models, shows that the impact of these models is often immediate and stable. The efficiency and quality of surgical care can be improved significantly with minimal investment in data collection, statistical analysis, personnel training, staff management and feedback at the right time $(18,42)$. Of course, significant improvements can be made in a short period of time and with relatively low resources, but commitment to continuous data collection, intervention, and awareness of the unintended consequences of these changes is essential. Also the leadership, continuous support and participation of the surgical management team will be necessary to facilitate and sustain quality improvement initiatives $(40,43)$.

The results of the studies showed that all first group models have the potential to use in the health system, especially in surgery (9). Due to these models entered from industry to the health, helps cost saving through reducing LOS and complications, continuous improvement (not instantaneous and short-term improvement) (44). It is notable that these models when applied in health, faces some challenges such as the necessity to clear identification of process and patient flow paths and allocate the required resources (45). One of the main weaknesses of these QI models is excessive simplification of the relationships between various steps of a process. Also, these models do not combine patient and system factors.

The second group of identified models is exclusively for surgery. Common feature of them is comprehensive and holistic view to the QI process (46). These models have highlighted the nature of health context and provided a method for effective organizational implementation and essential infrastructure to success $(47,48)$.

Hart framework in the second group can be implemented in all surgical fields easily. This model is a systematic approach to measure and standardize surgical care and achieve ideal care in any surgical field. Although this model is very useful and it can fill the known gaps in surgery, it has some limitations such as need to simplify surgical processes in order to use the model. All model components don't exist in all surgical processes. Also, various situations may happen that we can't fit them easily into the framework. However, the ability to organize complex processes and identify existing gaps has transformed this model into a tool for mapping surgery procedures in all surgical fields and provide a foundation for QI initiatives in surgery (33).

The results of reviewed studies revealed that using the QI models in surgery is increasing, and the purpose of using them is to reduce unnecessary consumption of resources, increase the satisfaction of patients and their families, improve the efficiency, quality and safety of healthcare in surgical wards. Also, the results showed that more focus has been done on determining the effectiveness of QI models in surgery so far (49-51).

It can be stated that using the first group models is wider than the second in surgery. This is perhaps due to the simplicity and ease of using them. It should be noted that there are differences in the context of countries, and the obstacles and limitations of each set to use the QI models are unique. The infrastructure, access to resources, priorities, and the challenges faced by countries are very different $(18,19)$. So it isn't possible to offer evidence-based recommendations for different conditions, because the most studies highlighted different aspects of the models to different fields, and in different settings (52-54).

Integration of the required infrastructure and their sustainability in QI initiatives are usually challenging (55). Three main factors that lead to successful implementation of the QI models include; changeable leadership, organizational culture, and teamwork. Of course, communication can be very difficult sometimes, and there are numerous examples of the lack of understanding changes. When implementing changes, continues leadership and regular monitoring and evaluating are essential (56).

Each of the identified models, had different approaches and aspects. Since the aim of our study was to review the QI models in surgical care rather than healthcare in its entirety, this creates an inherent selection bias in the search terms. For example, studies on infection control in medical patients may have been published, that could be attributed equally to surgical patients. Also, there are difficulties in conducting researches in this area. Publication bias is one of them. There may be studies that have unsuc- 
cessful results in quality improvement and therefore, were not published. On the other hand, some studies may not have been published despite successful results (18).

Heterogeneity of the studies in this field is one of the main limitations of our study; this makes it difficult to generalize findings. Also, the concept of QI challenged the sensitive search for this review. Moreover, there is a confusion of terminology and concepts about the QI models and methodologies and they are often used interchangeably -sometimes as synonyms and sometimes as two different approaches. We consider the methodology and model as a concept in this study. Moreover, the quality of care assessment and evaluation bias in reviewed studies is one of the study limitations.

Because only the peer-reviewed studies have been included, there may be other models in gray literature that have not been identified. Also due to the complexity of the type of studies and surgical environments, a detailed description of these models is not provided. Also, the frequency of using the models in the reviewed studies cannot be the evidence for strength of them. It also worth mentioning that over time, disorders and ambiguities would be created in the model's definition, which will be solved by developing and adding new parts into them (18). In total, there are several challenges in using and implementing the QI models in surgery; for example, wide range of patient problems, extensive procedures, and unexpected events.

In total, the present study is ongoing work. The QI models are constantly evolving, even in different organizational cultures that may change. Finally, despite the existing limitations, this review has helped in integrating QI models in surgery and seeing them together.

\section{Conclusion}

Hospitals comprise a large proportion of expenditures in health system and operation room activities have the largest share in hospital expenditures. This has caused that surgery to be an attractive target for QI initiatives. Reducing inefficiencies in surgery-related processes and improving the quality of care, especially in the current economic crisis, is one of the requirements of budgetary and resource-poor health systems. There are different models and frameworks with different aspects and dimensions for QI in surgery, which is recommended to use either of these models alone or with each other for specific circumstances. The use of these models in surgery is increasing, and it is recommended that these models could be used according to their functions in cases such as reducing the unnecessary use of resources, increasing the satisfaction of patients and their families with health care and improving the efficiency, safety and quality of healthcare in the surgical departments.

\section{Acknowledgments}

This study was part of a $\mathrm{PhD}$ thesis supported by the School of Health Management, Iran University of Medical Sciences, Iran (IUMS/SHMIS_1397-3-37-12899).

Ethics code (IR.IUMS.REG.1397.601)
Conflict of Interests

The authors declare that they have no competing interests.

\section{References}

1. Organization World Health, Everybody business: strengthening health systems to improve health outcomes: WHO's framework for action, 2007. Geneva: World Health Organization, 2014.

2. Counte MA, Meurer S. Issues in the assessment of continuous quality improvement implementation in health care organizations. Int J Qual Health C. 2001;13(3):197-207.

3. Harrigan M. Quest for quality in Canadian health care: Continuous quality improvement. Book. 2000.

4. Laffel G, Blumenthal D. The case for using industrial quality management science in health care organizations. Jama. 1989;262(20):2869-2873.

5. Lindenauer PK, Remus D, Roman S, Rothberg MB, Benjamin EM, Ma A, et al. Public reporting and pay for performance in hospital quality improvement. N Engl J Med. 2007;356(5):486-496.

6. Stulberg JJ, Delaney CP, Neuhauser DV, Aron DC, Fu P, Koroukian SM. Adherence to surgical care improvement project measures and the association with postoperative infections. Jama. 2010;303(24):2479-2485

7. Information CIfH, National Health Expenditure Trends, 1975-2003: Canadian Institute for Health Information, Institute Canadian information, 2003.

8. Haynes AB, Weiser TG, Berry WR, Lipsitz SR, Breizat AHS, Dellinger EP, et al. A surgical safety checklist to reduce morbidity and mortality in a global population. N Engl J Med. 2009;360(5):491499.

9. Minami CA, Sheils CR, Bilimoria KY, Johnson JK, Berger ER, Berian JR, et al. Process improvement in surgery, Current problems in surgery. Curr Probl Diagn Radiol. 2016;53(2):62-96.

10. Bickler SW, Spiegel D. Improving surgical care in low-and middleincome countries: a pivotal role for the World Health Organization. World J Surg. 2010;34(3):386-390

11. Ozgediz D, Jamison D, Cherian M, McQueen K. The burden of surgical conditions and access to surgical care in low-and middleincome countries. Bull World Health Organ. 2008;86:646-647.

12. Donabedian A. Evaluating the quality of medical care. Milbank Mem Fund Q. 1966;44(3):166-206.

13. Arah OA, Klazinga NS, Delnoij DM, Asbroek At, Custers T. Conceptual frameworks for health systems performance: a quest for effectiveness, quality, and improvement. Int $\mathrm{J}$ Qual Health $\mathrm{C}$. 2003;15(5):377-398.

14. Cameron DB, Rangel SJ. Quality improvement in pediatric surgery. Curr Opin Pediatr. 2016;28(3):348-355.

15. Newcombe J, Fry-Bowers E. Improving Postoperative Neonatal Nutritional Practices in an Intensive Care Unit Using the PDSA Cycle. J Pediatr Health Care. 2018;32(5):426-434

16. Tague NR. The quality toolbox, ASQ Quality Press Milwaukee, 2005.

17. Fong S. The application of quality improvement methodologies in surgery. Univ West Ontario Med J. 2017;86(2):37-39.

18. Nicolay C, Purkayastha S, Greenhalgh A, Benn J, Chaturvedi S, Phillips N, et al. Systematic review of the application of quality improvement methodologies from the manufacturing industry to surgical healthcare. Br J Surg. 2012;99(3):324-335.

19. Mason S, Nicolay C, Darzi A. The use of Lean and Six Sigma methodologies in surgery: a systematic review. The Surgeon. 2015;13(2):91-100.

20. Liberati A, Altman DG, Tetzlaff J, Mulrow C, Gøtzsche PC, Ioannidis JP, et al. The PRISMA statement for reporting systematic reviews and meta-analyses of studies that evaluate health care interventions: explanation and elaboration. PLoS Med. 2009;6(7):e1000100

21. Peters MD, Godfrey CM, Khalil H, McInerney P, Parker D, Soares CB. Guidance for conducting systematic scoping reviews. Int J Evid Based Healthc. 2015;13(3):141-146.

22. Elo S, Kyngäs $\mathrm{H}$. The qualitative content analysis process. J Adv Nurs. 2008;62(1):107-115.

23. Varkey P, Reller MK, Resar RK. Basics of quality improvement in health care. Mayo Clin Proc. 2007;2007:735-739.

24. Lawal AK, Rotter T, Kinsman L, Sari N, Harrison L, Jeffery C, et al. 
Lean management in health care: definition, concepts, methodology and effects reported (systematic review protocol). Syst Rev. 2014;3(1):103.

25. Bush RW. Reducing waste in US health care systems. Jama. 2007;297(8):871-874

26. Kaplan GS. Waste not: the management imperative for healthcare. J Health C Manag. 2012;57(3):160-166.

27. Cima RR, Brown MJ, Hebl JR, Moore R, Rogers JC, Kollengode A, et al. Use of lean and six sigma methodology to improve operating room efficiency in a high-volume tertiary-care academic medical center. J Am Coll Surg. 2011;213(1):83-92.

28. Cendán JC, Good M. Interdisciplinary work flow assessment and redesign decreases operating room turnover time and allows for additional caseload. Arch Surg. 2006;141(1):65-69.

29. Bader MK, Palmer S, Stalcup C, Shaver T. Using a FOCUS-PDCA quality improvement model for applying the severe traumatic brain injury guidelines to practice: process and outcomes. Evid-Based Nurs. 2003;6(1):6-8.

30. Fields D, Roman PM. Total quality management and performance in substance abuse treatment centers. Health Serv Res. 2010;45(6p1):1630-1649.

31. McLaughlin CP, Kaluzny AD. Continuous quality improvement in health care: theory, implementation, and applications. Jones \& Bartlett Learning, 2004.

32. Cua KO, McKone KE, Schroeder RG. Relationships between implementation of TQM, JIT, and TPM and manufacturing performance. J Oper Manag. 2001;19(6):675-694.

33. Hart CK, Ishman SL, Alessandrini E. Surgical measurement framework: A new framework for quality care in surgical specialties. Perioper Care Oper Room Manag. 2016;2:28-33.

34. Berry S, Doll M, McKinley K, Casale AS, Bothe A. ProvenCare: quality improvement model for designing highly reliable care in cardiac surgery. BMJ Qual \& Saf. 2009;18(5):360-368.

35. Luckenbaugh AN, Miller DC, Ghani KR. Collaborative quality improvement. Curr Opin Urol. 2017;27(4):395-401.

36. Mazzocato P, Holden RJ, Brommels M, Aronsson H, Bäckman U, Elg M, et al. How does lean work in emergency care? A case study of a lean-inspired intervention at the Astrid Lindgren Children's hospital, Stockholm, Sweden. BMC health services research, 2012, 12(1):28.

37. Zimnicki KM: Preoperative Teaching and Stoma Marking in an Inpatient Population. J Wound Ostomy Cont. 2015;42(2):165-169.

38. Mazaleski A. Postoperative total joint replacement class for support persons: Enhancing patient and family centered care using a quality improvement model. Orthop Nurs. 2011;30(6):361-364.

39. Buck D, Subramanyam R, Varughese A. A quality improvement project to reduce the intraoperative use of single-dose fentanyl vials across multiple patients in a pediatric institution. Pediatr Anesth. 2016;26(1):92-101.

40. Conaty O, Gaughan L, Downey C, Carolan N, Brophy MJ, Kavanagh R, et al. An interdisciplinary approach to improve surgical antimicrobial prophylaxis. Int $\mathrm{J}$ Healthcare Qual Assur. 2018;31(2):162-172.

41. Sedlack JD. The utilization of six sigma and statistical process control techniques in surgical quality improvement. J Healthc Qual.
2010;32(6):18-26

42. Scott JW, Nyinawankusi JDA, Enumah S, Maine R, Uwitonze E, Hu $\mathrm{Y}$, et al. Improving prehospital trauma care in Rwanda through continuous quality improvement: an interrupted time series analysis. Injury. 2017;48(7):1376-1381.

43. D'Andreamatteo A, Ianni L, Lega F, Sargiacomo M. Lean in healthcare: A comprehensive review. Health Policy. 2015;119(9):1197-1209.

44. Waljee JF, Birkmeyer NJ. Collaborative quality improvement in surgery. Hand Clin. 2014;30(3):335-343.

45. Young T, Brailsford S, Connell C, Davies R, Harper P, Klein JH. Using industrial processes to improve patient care. BMJ. 2004;328(7432):162-164

46. Schouten LM, Hulscher ME, van Everdingen JJ, Huijsman R, Grol RP: Evidence for the impact of quality improvement collaboratives: systematic review. BMJ. 2008;336(7659):1491-1494.

47. Powell A, Rushmer R, Davies H. A systematic narrative review of quality improvement models in health care: NHS Quality Improvement Scotland; 2009.

48. Øvretveit J. Does improving quality save money. A review of evidence of which improvements to quality reduce costs to health service providers London: The Health Foundation, 2009, 95.

49. DelliFraine JL, Langabeer JR, Nembhard IM. Assessing the evidence of Six Sigma and Lean in the health care industry. Qual Manag Health Care. 2010;19(3):211-225.

50. Thor J, Lundberg J, Ask J, Olsson J, Carli C, Härenstam KP, et al. Application of statistical process control in healthcare improvement: systematic review. BMJ Qual \& Saf. 2007;16(5):387-399.

51. Vest JR, Gamm LD. A critical review of the research literature on Six Sigma, Lean and StuderGroup's Hardwiring Excellence in the United States: the need to demonstrate and communicate the effectiveness of transformation strategies in healthcare. Implement Sci. 2009;4(1):35.

52. Fan E, Laupacis A, Pronovost PJ, Guyatt GH, Needham DM. How to use an article about quality improvement. JAMA. 2010;304(20):22792287.

53. Davidoff F, Batalden P, Stevens D, Ogrinc G, Mooney S. Publication guidelines for quality improvement in health care: evolution of the SQUIRE project. BMJ Qual Saf. 2008;17(Suppl 1): 3-9.

54. Ogrinc G, Mooney S, Estrada C, Foster T, Goldmann D, Hall LW, et al. The SQUIRE (Standards for QUality Improvement Reporting Excellence) guidelines for quality improvement reporting: explanation and elaboration. BMJ Qual Saf. 2008;17(1): 13-32.

55. Marshall DA, Christiansen T, Smith C, Squire Howden J, Werle J, Faris $\mathrm{P}$, et al. Continuous quality improvement program for hip and knee replacement. Am J Med Qual. 2015;30(5):425-431.

56. Divi V, Chen MM, Hara W, Shah D, Narvasa K, Segura Smith A, et al. Reducing the Time from Surgery to Adjuvant Radiation Therapy: An Institutional Quality Improvement Project. Otolaryngol Head Neck Surg. 2018;159(1):158-165.

((Improvement AND Quality) OR (Improvements AND Quality) OR (“Quality Improvements”) OR (“Quality Improvement”) OR (Management AND total quality) OR ("quality improvement") OR ("quality management") [Ti/Ab]) AND ((“Operative Surgical Procedure") OR (Surgery) OR ("Operative Surgical Procedures") OR (Procedures AND “Operative Surgical”) OR ("Surgical Procedure” AND Operative) OR (“Operative Procedures") OR ("Operative Procedure") OR (Procedure AND Operative) OR (Procedures AND Operative) OR (Procedure AND “Operative Surgical") OR (Diagnosis AND surgical) OR ("diagnostic techniques" AND surgical) OR (operation) OR ("operation care”) OR ("operative intervention”) OR ("operative repair") OR ("operative restoration") OR ("operative surgical procedure") OR ("operative treatment") OR ("research surgery") OR (specialties AND surgical) OR (surgery AND operative) OR ("surgical care") OR ("surgical intervention") OR ("surgical management") OR ("surgical operation") OR ("surgical practice") OR ("surgical procedures" AND operative) OR ("surgical repair") OR ("surgical research") OR ("surgical service") OR ("surgical speciality") OR ("surgical specialty") OR ("surgical therapy") OR ("surgical treatment") OR theatre [Title/Abstract]) AND (model* OR framework*)[Title/Abstract]) 